Submission: 25-10-2018; Revision: 03-11-2018; Published: 16-11-2018

Available online at: http://e-journal.upstegal.ac.id/index.php/jip

Doi: http://dx.doi.org/10.24905/jip.v3i2.1037

\title{
Analisa Strategi Pengembangan Kota Pintar (Smart City): Studi Kasus Kota Yogyakarta
}

\author{
Nur Faidati1) *, Muhammad Khozin 2) \\ 1 Program Studi Administrasi Publik, Universitas 'Aisyiyah Yogyakarta, Jl. Ringroad Barat No.63 \\ Mlangi, Nogotirto Gamping Yogyakarta 55291 \\ 2 Program Studi Administrasi Publik, Universitas ‘Aisyiyah Yogyakarta, Jl. Ringroad Barat No.63 \\ Mlangi, Nogotirto Gamping Yogyakarta 55291
}

* Korespondensi Penulis. E-mail: nurfaidati@unisajogja.ac.id, Telp: +628175499880

\begin{abstract}
Abstrak
Studi ini bermaksud mencermati strategi yang dilakukan oleh Pemerintah Kota Yogakarta dalam mengembangkan kota menjadi kota pintar (smart city). Penelitian ini menggunakan metode penelitian deskriptif kualitatif. Penelitian ini menggunakan teknik pengumpulan data studi pustaka (desk study) dan wawancara (interview). Studi pustaka dilakukan melalui pelacakan data sekunder. Wawancara dilakukan dengan organisasi perangkat daerah (OPD) yang berperan sebagai leading sector dalam pengembangan smart city serta OPD lain yang memiliki keterkaitan dengan pengembangan smart city. Dari penelitian yang dilakukan, diketahui bahwa pengembangan smart city di Kota Yogyakarta dilakukan dengan melanjutkan atau memanfaatkan apa yang sudah dilakukan oleh Pemerintah Kota Yogyakarta terutama terkait dengan pemanfaatan TIK dalam penyediaan pelayanan publik serta menjalin kemitraan dengan stakeholder lain yang memiliki keterkaitan dengan pengembangan smart city.
\end{abstract}

Kata Kunci: Smart City, Pengembangan Kota, Perencanaan Kota

\begin{abstract}
This study intends to examine the strategies carried out by the Government of the City of Yogyakarta in developing the city into a smart city. This study uses a qualitative descriptive research method. This study uses a desk study and interview technique. Library studies are carried out through secondary data tracking. Interviews were conducted with regional apparatus organizations (OPD) which acted as the leading sector in the development of smart cities and other OPDs that were related to the development of smart cities. From the research conducted, it is known that the development of smart cities in the city of Yogyakarta is carried out by continuing or utilizing what has been done by the Yogyakarta City Government, especially related to the use of ICT in the provision of public services and establishing partnerships with other stakeholders that are related to smart city development.
\end{abstract}

Key Word: Smart City, City Development, Urban Planning 


\section{Jurnal Ilmu Pemerintahan: Kajian Ilmu Pemerintahan dan Politik Daerah, 3 (2), \\ Oktober 2018 - 172 \\ Nur Faidati1) *, Muhammad Khozin ${ }^{2)}$}

\section{Pendahuluan}

Masuknya Kota Yogyakarta sebagai 10 Destinasi terbaik di Indonesia menurut Traveller's Choice Award 2017 membuat Kota Yogyakarta terus berbenah dalam menata dan mengembangkan pariwisata di Yogyakarta. Melihat potensi besar yang terdapat di berbagai sektor seperti pendidikan, pariwisata, teknologi serta partisipasi aktif masyarakat Yogyakarta, kemudian Pemerintah Kota Yogyakarta bersama dengan Pemerintah Pusat bekerja sama mengembangkan Yogyakarta sebagai kota pintar (Smart City).

Kota Yogyakarta dan Sleman ditunjuk sebagai Pilot Project kota pintar (Smart City) bersama dengan Kota Semarang, Serang, Tangerang, Depok, Bekasi, Sidoarjo, Kudus dan Surakarta. Penunjukkan kota Yogyakarta sebagai Pilot Project kemudian ditindaklanjuti dengan serius oleh Pemerintah Kota Yogyakarta dengan membentuk kelompok kerja Kota Pintar (Smart City) yang terdiri dari unsurunsur akademisi, pemerintah, swasta, dan masyarakat.

Konsep pengembangan Kota Pintar (Smart City) di Yogyakarta berbeda dengan pengembangan Kota Pintar (Smart City) di kota lain. Kota Pintar (Smart City) Yogyakarta berada di bawah payung besar Smart Culture yang dibagi menjadi 2 bidang, yaitu Smart Education dan Smart Tourism. Konsep besar ini diambil karena selama ini kota Yogyakarta sangat kental dengan budayanya serta dikenal sebagai kota pendidikan dan kota pariwisata. Konsep Smart Culture diharapkan dapat menyentuh seluruh aspek kehidupan warga Yogyakarta yang tidak terlepas dari 6 prinsip dasar pengembangan Kota Pintar (Smart City), yakni Smart Environment, Smart Living, Smart People, Smart Economy, Smart Mobility dan Smart Governence.

Pengembangan konsep Kota Pintar (Smart City) di Yogyakarta dengan payung besar Smart Culture dinilai oleh tim PSPPR UGM sudah cukup sesuai dengan visi kota Yogyakarta yakni, "Terwujudnya Kota Pendidikan Berkualitas, Berkarakter dan Insklusif, Pariwisata Berbasis Budaya, dan Pusat Pelayanan Jasa, yang berwawasan Lingkungan dan Ekonomi Kerakyatan." Tim PSPPR mengungkapkan bahwa visi kota Yogyakarta memiliki 4 kata kunci yakni pariwisata, pendidikan, budaya dan pusat pelayanan jasa, empat kata kunci tersebut kemudian dikembangkan menjadi dasar konsep Smart Culture.

Menurut Stephen Ezell (Vice President Global Innovation Policy Information Technology and Innovation Faoundation), salah satu keuntungan konsep Kota Pintar (Smart City) adalah dapat menciptakan perencanaan dan pengembangan kota layak huni yang lebih baik di masa depan, konsep Kota Pintar (Smart City) juga membuat layanan $e$ government dapat lebih cepat implikasinya kepada masyarakat, konsep Kota Pintar 


\section{Jurnal Ilmu Pemerintahan: Kajian Ilmu Pemerintahan dan Politik Daerah, 3 (2), \\ Oktober 2018 - 173 \\ Nur Faidati1) *, Muhammad Khozin ${ }^{2)}$}

(Smart City) juga dapat membuat sistem transportasi lebih efisien dan terintegrasi sehingga meningkatkan mobilitas masyarakatnya, menciptakan rumah dan bangunan yang hemat energy, lingkungan juga bisa menjadi lebih lestari karena konsep pengaturan limbah dan pengelolaan air yang lebih maju, Kota Pintar (Smart City) juga akan meningkatkan kesejahteraan masyarakat dan peningkatan pelayanan kesehatan.

Penerapan Kota Pintar (Smart City) di Yogyakarta dan di Indonesia bukan tanpa hambatan dan kelemahan. Kelemahan yang mendasar dalam penerapan Kota Pintar (Smart City) yakni pada regulasi, karena pada saat ini penerapan Kota Pintar (Smart City) hanya bersandar pada payung hukum e-government. Diharapkan dengan adanya Undang- Undang Kota Pintar (Smart City), Pemerintah Daerah dapat dengan maksimal memberikan pelayanan kepada masyarakat, serta dapat mendapatkan dasar aturan dalam pengembangan Kota Pintar (Smart City). Berdasarkan urgensi permasalahan di atas, maka penelitian ini ingin mengkaji lebih mendalam mengenai bagaimana strategi pengembangan Kota Pintar (Smart City) yang dilakukan oleh Pemerintah Kota Yogyakarta?

\section{Metode}

Penelitian ini ditujukan untuk mengetahui serta menguji strategi yang telah ditempuh Pemerintah Kota Yogyakata dalam tahap pengembangan Kota Yogyakarta menjadi Kota Pintar (Smart City). Penelitian ini dilakukan pada bulan Juli-Oktober 2018, di lingkungan Pemerintah Kota Yogyakarta. Penelitian ini menggunakan metode penelitian deskriptif kualitatif. Adapun metode pengumpulan data yang digunakan dalam penelitian ini adalah studi pustaka (desk study) dan wawancara (interview). Studi Pustaka (desk study) digunakan untuk melacak arsiparsip terkait persoalan yang di teliti, yaitu aturan perundang-undangan (nasional maupun lokal), surat, memorandum, catatan pertemuan, dokumen administratif, pengumuman, kliping, berita maupun artikel-artikel yang berasal dari media, dan sebagainya. Studi pustaka juga dilakukan melacak literatur-literatur terdahulu, seperti buku, laporan penelitian, karya akademik, dan sejenisnya, yang memiliki keterkaitan dengan persoalan yang sedang diteliti. Wawancara (interview) dilakukan untuk menggali informasi dari pihak yang terlibat dalam proses penyusunan dokumen. Adapun responden dari wawancara ini adalah organisasi perangkat daerah (OPD) di lingkungan Pemerintah Kota Yogyakarta yang menjadi penanggungjawab pengembangan smart city di Yogyakarta, diantaranya adalah Bappeda, Dinas Komunikasi dan Informatika, serta sejumlah OPD lain yang mendukung 


\section{Jurnal Ilmu Pemerintahan: Kajian Ilmu Pemerintahan dan Politik Daerah, 3 (2), \\ Oktober 2018 - 174 \\ Nur Faidati1) *, Muhammad Khozin ${ }^{2)}$}

pengembangan smart city di Kota Yogyakarta.

Adapun metode analisis data yang digunakan adalah deskriptif kualitatif. Dari data yang berhasil dikumpulkan melalui wawancara, pengamatan yang sudah dituliskan dalam catatan lapangan, dokumen pribadi, dokumen resmi, gambar, foto, kemudian ditelaah, dirangkum dan dipilih hal-hal yang pokok sesuai dengan kerangka teori yang sudah ditentukan.

Selanjutnya, data dan informasi yang sudah dipilih, disajikan untuk memberikan gambaran strategi yang dilakukan oleh Pemerintah Kota Yogyakarta dalam mengembangkannya menjadi kota pintar (Smart City). Dari proses tersebut kemudian dilakukan penarikan kesimpulan berdasarkan proses verifikasi dari subyek penelitian dengan kerangka konsep yang telah ditentukan.

\section{Hasil Dan Pembahasan}

Dalam pengembangan smart city di Kota Yogyakarta sebetulnya telah mulai dilakukan sejak awal tahun 2000-an, sebelum konsep smart city populer. Hal tersebut setidaknya dapat dilacak dari penggunaan unit pelayanan informasi dan keluhan (UPIK) sebagai bagian dari penerapan open government di Kota Yogyakarta. Layanan UPIK mulai dirintis tahun 2003 dan diluncurkan pada 31 Januari 2004. Layanan UPIK merupakan media untuk menampung aspirasi masyarakat sehingga pemerintah dapat mengetahui permasalahan yang ada di masyarakat.

Setelah layanan UPIK ini berhasil dimanfaatkan oleh Pemerintah Kota Yogyakarta untuk menampung aspirasi masyarakat, muncul sejumlah layanan lain yang menunjang pengembangan Kota Yogyakarta sebagai kota pintar (smart city). Diantara layanan tersebut adalah SIM Pelayanan Kesehatan, Layanan YES 118, Konsultasi Belajar Siswa Online, Digital Library, Sistem Penerimaan Siswa Baru, Taman Pintar Yogyakarta, Hi Jogja, Whistle Blower System, SIM POS PBB, SIM MAPATDA, SIM Pasar, Sim Retribusi Pasar dan sejumlah aplikasi lain yang mampu mengefisienkan dan mengefektifkan penggunaan sumber daya dalam penyediaan pelayanan publik bagi masyarakat, meningkatkan kualitas pelayanan publik dan memberikan kemudahan bagi masyarakat untuk mengakses layanan publik yang disediakan oleh Pemerintah Kota Yogyakarta.

Lebih lanjut, untuk memberikan payung hukum yang mewadahi pengembangan aplikasi sebagaimana disebutkan di atas, pada tahun 2015, Pemerintah Kota Yogyakarta menerbitkan Peraturan Walikota Yogyakarta No. 15 Tahun 2015 tentang E-Government. EGovernment dalam konteks ini dimaknai sebagai penyelenggaraan kepemerintahan yang berbasis (menggunakan) elektronik 


\section{Jurnal Ilmu Pemerintahan: Kajian Ilmu Pemerintahan dan Politik Daerah, 3 (2), \\ Oktober 2018 - 175 \\ Nur Faidati1) *, Muhammad Khozin ${ }^{2)}$}

dalam rangka meningkatkan kualitas layanan publik secara efektif dan efisien (Pasal 1 Peraturan Walikota Yogyakarta No. 15 Tahun 2015).

Secara umum penerbitan produk hukum dalam bentuk peraturan walikota ini menjadi tonggak dalam pengembangan smart city di Kota Yogyakarta. Di dalam peraturan walikota ini pula dituangkan masterplan (roadmap) pengembangan $E$ Government di Kota Yogyakarta periode tahun 2016-2031. Adapun pentahapan dari masterplan ini adalah sebagai berikut:

Tabel 1. Pentahapan Masterplan EGovernment Pemerintah Kota Yogyakarta

\begin{tabular}{|c|c|}
\hline Pentahapan & Fokus \\
\hline $\begin{array}{l}\text { Tahap I (2016- } \\
\text { 2018) }\end{array}$ & $\begin{array}{l}\text { Penguatan infrastruktur jaringan } \\
\text { dan pusat data }\end{array}$ \\
\hline $\begin{array}{l}\text { Tahap II (2019- } \\
\text { 2021) }\end{array}$ & $\begin{array}{l}\text { Penguatan infrastruktur sistem } \\
\text { informasi }\end{array}$ \\
\hline $\begin{array}{l}\text { Tahap III (2022- } \\
\text { 2024) }\end{array}$ & $\begin{array}{l}\text { Integrasi data dan pengembangan } \\
\text { aplikasi terintegrasi }\end{array}$ \\
\hline $\begin{array}{l}\text { Tahap IV (2025- } \\
\text { 2027) }\end{array}$ & Data Warehouse \\
\hline 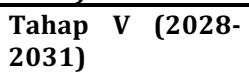 & $\begin{array}{l}\text { Implementasi kebijakan menuju } \\
\text { smart city }\end{array}$ \\
\hline
\end{tabular}

Meskipun telah terbit dokumen yang menjadi dasar hukum pengembangan smart city di Kota Yogyakarta dalam bentuk Peraturan Walikota, namun dokumen tersebut belum secara eksplisit menjabarkan dengan lebih terperinci tentang smart city yang mencakup 7 dimensi yaitu: smart economy, smart people, smart governance, smart mobility, smart environment, smart living dan smart disaster management beserta indikator/tolok ukurnya masing-masing.
Oleh karena itu, pada tahun 2016 Pemerintah Kota Yogyakarta menyusun kajian road map Kota Yogyakarta menuju smart city.

Adapun maksud dari penyusunan kajian road map Kota Yogyakarta menuju smart city adalah sebagai instrumen dalam pengambilan kebijakan, perencanaan program dan kegiatan yang mendukung Yogyakarta smart city agar saling terintegrasi dan sinkron sehingga tercipta sinergitas antara seluruh instansi di Pemerintah Kota Yogyakarta dengan masyarakat, Menjaga keterkaitan dan konsistensi antara kebijakan, perencanaan, penganggaran, pelaksanaan, pengendalian dan pengawasan dalam program dan kegiatan untuk Yogyakarta Smart City serta mengoptimalkan peran serta masyarakat dalam pengambilan kebijakan serta perencanaan program dan kegiatan yang mendukung Yogyakarta Smart City (Road Map Kota Yogyakarta Menuju Kota Pintar (Smart City), Tim PSPPR UGM; 2016).

Adapun Sasaran yang hendak dicapai melalui Kajian Smart City ini adalah:

1. Mengidentifikasi potensi dan permasalahan yang dimiliki Kota Yogyakarta berdasarkan 7 dimensi Smart City;

2. Menyusun indikator-indikator /tolok ukur Smart City berdasarkan hasil identifikasi potensi dan permasalahan yang 
Jurnal Ilmu Pemerintahan: Kajian Ilmu Pemerintahan dan Politik Daerah, 3 (2),

Oktober 2018 - 176

Nur Faidati1) *, Muhammad Khozin ${ }^{2)}$

sesuai dengan kondisi Kota

(Sumber: Road Map Kota Yogyakarta Menuju Kota Pintar (Smart City), Tim PSPPR UGM)

Yogyakarta;

3. Menyusun Road Map Kota Yogyakarta menuju Smart City;

4. Melakukan penilain (assessment) terhadap kondisi Kota Yogyakarta untuk mengetahui posisi dan kesiapan Kota Yogyakarta menuju Smart City.

Berdasarkan kajian tersebut, diketahui bahwa pengembangan Kota Yogyakarta menjadi kota pintar didasarkan pada visi Kota Yogyakarta "Kota Pendidikan-Berkualitas, Berkarakter dan Inklusif, Pariwisata Berbasis Budaya, dan Pusat Pelayanan Jasa, yang Berwawasan Lingkungan dan Ekonomi Kerakyatan". Visi tersebut memiliki 4 (empat) kata kunci yakni pariwisata, pendidikan, budaya dan pusat pelayanan jasa. Empat kata kunci inilah yang akan dikembangkan sebagai sebuah tujuan pengembangan smart city di Kota Yogyakarta, dengan payung utama yaitu smart culture.

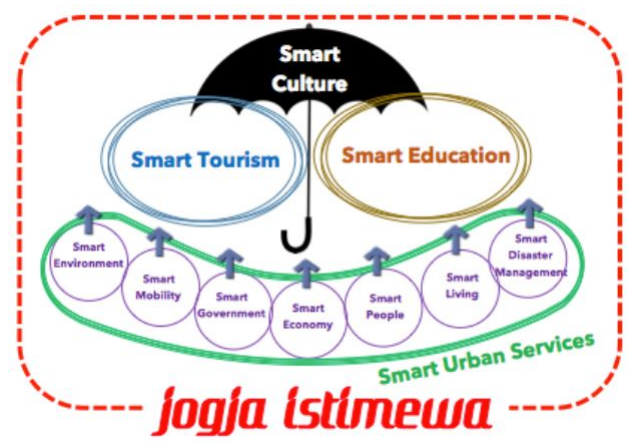

Gambar 1. Konsep Pengembangan Smart City

\footnotetext{
${ }^{1}$ Road Map Kota Yogyakarta Menuju Kota Pintar (Smart City), Tim PSPPR UGM
}

Guna mencapai Yogyakarta smart culture, diperlukan beberapa agenda kerja yang harus dilaksanakan dalam kurun waktu 5 (lima) tahun ke depan. Tahapan pelaksanaan beberapa agenda kerja tersebut terbagi menjadi 2 (dua), yaitu jangka pendek dengan kurun waktu 1-2 tahun ke depan, dan jangka menengah dengan kurun waktu 3-5 tahun ke depan. Berikut ini adalah pentahapan smart city di Kota Yogyakarta:

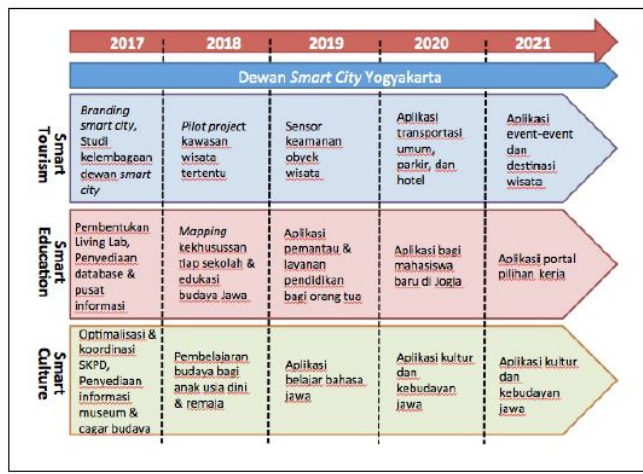

Gambar 2. Pentahapan Smart City Kota Yogyakarta

Sumber: Road Map Kota Yogyakarta Menuju Kota Pintar (Smart City), Tim PSPPR UGM

Selain dilakukan pentahapan smart city Yogyakarta, perlu adanya penguatan Yogyakarta smart city yang bertujuan untuk memantapkan langkah Kota Yogyakarta dalam mewujudkan Yogyakarta smart city. Penguatan Yogyakarta smart city dibagi menjadi tiga fokus utama, yaitu' ${ }^{1}$ :

Penyelarasan Kebijakan dan Strategi Yogyakarta Smart City 


\section{Jurnal Ilmu Pemerintahan: Kajian Ilmu Pemerintahan dan Politik Daerah, 3 (2), \\ Oktober 2018 - 177 \\ Nur Faidati1) *, Muhammad Khozin ${ }^{2)}$}

Penyelarasan kebijakan dan strategi Yogyakarta Smart City dilakukan melalui sinkronisasi, harmonisasi, dan sinergi kebijakan Kota Yogyakarta. Penyusunan kebijakan dan strategi Yogyakarta Smart City dapat didahului dengan penyusunan Roadmap Yogyakarta Smart City. Roadmap Yogyakarta Smart City diintegrasikan dalam RPJMD Kota Yogyakarta tahap ketiga yang akan disusun, sehingga apabila kebijakan, strategi, tujuan, sasaran, maupun program tercakup dalam RPJMD Kota Jogja tahap ketiga, maka prakarsa maupun inisiatif Yogyakarta Smart City dapat diakomodasi dalam penyusunan RKPD Kota Yogyakarta maupun Rencana Strategis OPD terkait.

Dengan demikian implementasi Yogyakarta Smart City melalui program maupun kegiatan yang dilaksanakan oleh OPD terkait dapat terwujud.

\section{Penataan Unsur Yogyakarta Smart City}

Penataan unsur Yogyakarta Smart City meliputi kelembagaan, jejaring, dan sumberdaya smart city. Penataan Kelembagaan Yogyakarta Smart City harus mempertimbangkan organisasi, regulasi, maupun norma/etika/budaya.

Pertimbangan organisasi yang diperlukan untuk merumuskan kebijakan dan arahan strategis pembangunan dan pengembangan Yogyakarta Smart City adalah Dewan Smart City Yogyakarta. Dewan Smart City Jogja berperan sebagai mitra Pemerintah Kota Jogja (GovernmentCIO) dalam pembangunan dan pengembangan smart city.

Pembentukan 'Dewan Smart City Yogyakarta' perlu memperhatikan kapasitas, peran, dan dukungan anggaran. Regulasi Yogyakarta Smart City perlu disusun terutama terkait berbagi sumberdaya TIK, pendanaan, dokumentasi, maupun pedoman kerjasama/investasi bagi pihak ketiga. Jogja Smart City juga perlu memperhatikan norma/etika/budaya setempat yang berdasar profesionalisme.

Penataan jejaring Yogyakarta Smart City dilakukan melalui interaksi dan sinergi pemangku kepentingan: Academic, Business, Community, Government, dan Media. Penataan sumberdaya Yogyakarta Smart City dilakukan melalui penataan brainware, software, dan hardware.

Penataan brainware perlu memperhatikan kepakaran, keahlian, kompetensi, dan ketrampilan. Penataan software dan hardware perlu memperhatikan interoperabilitas, skalabilitas, dan realibilitas.

\section{Pembangunan dan Pengembangan Yogyakarta Smart City}

Pembangunan dan Pengembangan Yogyakarta Smart City dapat dilakukan melalui komitmen dan konsensus unsur Yogyakarta Smart City; pemetaan potensi dan analisis Yogyakarta Smart City, 
Jurnal Ilmu Pemerintahan: Kajian Ilmu Pemerintahan dan Politik Daerah, 3 (2),

Oktober 2018 - 178

Nur Faidati1) *, Muhammad Khozin ${ }^{2)}$

penciptaan keselarasan antara proses bisnis dan TIK menggunakan Enterprise Architecture (proses bisnis, sistem, teknologi, aplikasi, data, SDM, dan organisasi); pengelolaan sumberdaya Jogja Smart City (meliputi brainware, software, dan hardware); tata kelola (Business, IT (termasuk keamanan), dan Process) dan manajemen (termasuk manajemen perubahan dan manajemen resiko) Yogyakarta Smart City; penyusunan branding (misal Yogyakarta Smart City, Yogyakarta Digital City, Great Yogyakarta, iYogyakarta, atau e-Yogyakarta, dll), pembangunan Living Lab Yogyakarta Smart City; pemberlanjutan pembangunan dan pengembangan Yogyakarta Smart City.

Living Lab Yogyakarta Smart City merupakan komitmen, peran serta, dan pengabdian PTN/PTS di Yogyakarta dalam pendayagunaan TIK untuk implementasi Yogyakarta Smart City sehingga diharapkan dapat memperbaiki tata kelola Pemerintah Kota Yogyakarta yang lebih baik dan lebih cerdas dalam memberikan pelayanan prima di bidang pemerintahan, kemasyarakatan, maupun pembangunan.

\section{SIMPULAN DAN SARAN}

\section{Simpulan}

Strategi Pengembangan Smart City yang dilakukan oleh Pemerintah Kota Yogyakarta secara umum dilakukan dengan melanjutkan atau memanfaatkan apa yang sudah dilakukan oleh Pemerintah Kota Yogyakarta terutama terkait dengan pemanfaatan TIK dalam penyediaan pelayanan publik. Dari proses tersebut, aplikasi yang sudah mulai dibangun sejak awal tahun 2000 telah dikembangkan dan diintegrasikan dalam konsep single $I D$, single window, single sign on yang dikebangkan untuk semua layanan dan diwujudkan dalam bentuk aplikasi android Jogja Smart Services (JSS).

Aplikasi tersebut memuat fitur yang sudah dikembangkan sebelumnya, yang meliputi layanan kedaruratan, layanan aduan, layanan pajak, layanan pendidikan, layanan kesehatan dan sejumlah layanan baru yang lain. Pembuatan JSS ini sekaligus disinkronkan dengan rancangan masterplan smart city yang saat ini tengah dimatangkan oleh Pemerintah Kota Yogyakarta.

Lebih lanjut, pengembangan smart city di kota yogyakarta ini dilakukan dengan menjalin kemitraan dengan stakeholder lain yang memiliki keterkaitan dengan pengembangan smart city. Hal tersebut salah satunya dilakukan dengan Kementrian Komunikasi dan Informatika. Dari proses kemitraan tersebut, saat ini Pemerintah Kota Yogyakarta sedang mematangkan roadmap pengembangan Kota Yogyakarta menuju Kota Pintar (Smart City).

\section{Saran}

Pengembangan smart city di Kota Yogyakarta seharusnya tidak hanya 
Jurnal Ilmu Pemerintahan: Kajian Ilmu Pemerintahan dan Politik Daerah, 3 (2),

Oktober 2018 - 179

Nur Faidati1) *, Muhammad Khozin ${ }^{2)}$

diarahkan pada pemanfaatan TIK dalam pemberian pelayanan publik kepada masyarakat. Lebih dari itu, pengembangan smart city di Kota Yogyakarta seharusnya lebih ditekankan pada upaya memperbaiki kualitas kehidupan masyarakatnya. Bagaimana TIK itu dimanfaatkan tidak saja pada upaya untuk memberikan kemudahan dalam penyelenggaraan pelayanan publik, namun juga pada upaya memberitahu bahwa sedang timbul suatu masalah perkotaan di Kota Yogyakarta dan memberikan usulan tindakan otomatis (dimungkinkan oleh sistem actuator) atau tidak-otomatis untuk mengatasi masalah.

\section{DAFTAR PUSTAKA}

Alawiah, Enok Tuti. "Rancangan Aplikasi Smart City Berbasis Mobile Untuk Meningkatkan Kulitas Layanan Publik Studi Kasus Pemkot Bogor." Jurnal Teknik Komputer 3.1 (2017): 24-29.

Arif, Wahyudi (2016). Kota pintar, utamakan pelayanan publik, seluruh pejabat harus paham ini. Tersedia dari http://www.harianjogja.com/bac a/2016/10/13/kota-pintarutamakan-pelayanan-publikseluruh-pejabat-harus-pahamini-760295

Arif, Sodhiq (2017). Wujudkan Kota "Smart Tourism", ini konsep Pemkot Yogyakarta. Tersedia dari https://she.id/article/1612/wuj udkan-kota-smart-tourism-inikonsep-pemkot-yogyakarta.html

Chandra Eko., dan Mochamad Hariadi (2016). Strategi Pembangunan Smart City dan Tantangannya bagi Masyarakat Kota. Jurnal Strategi dan Bisnis Vol.4, No. 2
Istiyanto, Jazi Eko, and Edhy Sutanta. "Model Interoperabilitas Antar Aplikasi e-Government." Jurnal Technoscientia 5 (2012).

Jaya, Safitri. "Implementasi Dan Perkembangan E-Government di Indonesia." Jurnal Informatika Multimedia (JIM) 2.1 (2013): 3752.

Jonathan (2016). Apa itu Smart City?. Tersedia dari http://jonatan.blog.widyatama.a c.id/2016/03/13/apa-itu-smartcity/

Kurniawan, Teguh. "Hambatan dan Tantangan dalam Mewujudkan Good Governance melalui Penerapan E-Government di Indonesia." Prosiding Konferensi Nasional Sistem Informasi 2006 (2006).

MBC Design (2017). Membangun Smart City dengan pemanfaatan teknologi informasi. Tersedia dari https://designmbc.blogspot.co.id /2017/01/membangun-smartcity-dengan-pemanfaatan.html

Rahardjo, Budi. "Membangun $e$ government." Makalah dipresentasikan pada Seminar Nasional Jaringan Komputer II diselenggarakan oleh Technic Study Club, STMIK Dipanegara Makassar. Vol. 19. 2001.

Setijaningrum, Erna. (2009)."Inovasi Pelayanan Publik." Surabaya: PT Revka Petra Media

Sosiawan, Edwi Arief. "Tantangan dan Hambatan dalam implementasi $E$ Government di Indonesia." Seminar Nasional Informatika (SEMNASIF). Vol. 1. No. 5. 2015.

Suwarno, Yogi. (2008)."Inovasi di Sektor Publik." STIA-LAN, Jakarta

Sukyadi, Didi, 2009, Model Interoperabilitas sistem informasi pelayanan publik-Studi Kasus: E- 
Jurnal Ilmu Pemerintahan: Kajian Ilmu Pemerintahan dan Politik Daerah, 3 (2),

Oktober 2018 - 180

Nur Faidati1) *, Muhammad Khozin ${ }^{2)}$

Government, Karya Akhir,

Fasilkom UI.

Tim PSPPR UGM (2016). Road Map Kota

Yogyakarta Menuju Smart City.

Working Papper PSPPR.

Widodo, Nurjati. "Pengembangan eGovernment di Pemerintahan

Daerah Dalam Rangka

Mewujudkan Smart City (Studi di

Pemerintah Daerah Kota

Malang)." Jurnal Ilmiah

Administrasi Publik 2.4 (2016).

Wiwin, Purnomowati., Ismini (2014).

Konsep Smart City dan

Pengembangan Pariwisata Di

Kota Malang. Jurnal JIBEKA Vol.8

No. 1.

\section{Profile Penulis}

Nur Faidati, S.IP.,MA Sebagai staff pengajar pada Program Studi Administrasi Publik Universitas 'Aisyiyah Yogyakarta. Menyelesaikan studi S1 pada Jurusan Ilmu Administrasi Negara UGM, dan S2 Manajemen dan Kebijakan Publik UGM. Aktif melakukan penelitian dan kajian di bidang kebijakan publik dan studi pembangunan.

\section{Muhammad Khozin, S.IP.,MPA.}

Sebagai staff pengajar pada Program Studi Administrasi Publik Universitas 'Aisyiyah Yogyakarta. Menyelesaikan S1 pada Jurusan Ilmu Pemerintahan UMY, dan S2 pada Magister Administrasi Publik UGM. Aktif melakukan penelitian dan kajian pada bidang manajemen pelayanan publik dan kelembagaan sektor publik. 